\title{
Comparing the influences of age and disease on the Brief Assessment of Cognition in Schizophrenia in Japanese patients with schizophrenia
}

\author{
This article was published in the following Dove Press journal: \\ Neuropsychiatric Disease and Treatment \\ 13 August 2013 \\ Number of times this article has been viewed
}

\author{
Ayako Kaneda ${ }^{1,2}$ \\ Takeshi Katagai' \\ Norio Yasui-Furukori' \\ 'Department of Neuropsychiatry, \\ Hirosaki University Graduate \\ School of Medicine, Hirosaki, Japan; \\ ${ }^{2}$ Department of Psychiatry, Kuroishi- \\ Akebono Hospital, Kuroishi, Japan
}

Background: The Brief Assessment of Cognition in Schizophrenia (BACS) is an evaluation of cognitive function that can be completed with more cases. However, there are few studies that compare which factor, disease or aging, is a better determinant of performance on the BACS. The present study aimed to investigate the influences of disease and aging on BACS performance in schizophrenic patients using subjects with a wide range of ages.

Methods: Schizophrenic patients $(n=165)$ and a comparison group $(n=171)$ were recruited as subjects. All participants completed the Japanese language version of the BACS (BACS-J), and the influences of disease and aging on performance in the BACS were examined with the use of multiple regression analysis.

Results: There was a significant influence of diagnosis and level of education on all six tasks of the BACS and the performance and composite scores. In addition, age was found to influence five tasks and the composite score, the duration of illness influenced four tasks and the composite score, and gender influenced one task and the composite score.

Conclusion: The present study suggests that performance on the BACS was impaired not only by disease but also by level of education and aging.

Keywords: schizophrenia, cognition, age

\section{Background}

Cognitive impairments in schizophrenic patients can make it difficult to have a daily life or social rehabilitation because the impairment persists even after improvement of psychotic symptoms. Patients with chronic schizophrenia especially demonstrate impairments that range between one and a half to two standard deviations below healthy controls on verbal memory, working memory, motor speed, attention, executive functions, and verbal fluency. ${ }^{1}$

Many studies have investigated factors that influence cognitive function. Several studies have reported on the influence of aging on cognitive functions in schizophrenic patients. ${ }^{2,3}$ Furthermore, Bozikas et al and Sugawara et al reported an age related cognitive decline in healthy population by examination of the Clock Drawing Test (CDT) ${ }^{4,5}$ Previously, we investigated which factor, disease or aging, is a better determinant of cognitive function in schizophrenic patients using the CDT and reported that cognitive function is impaired not only by disease but also by aging. ${ }^{6}$

The Brief Assessment of Cognition in Schizophrenia (BACS) is an evaluation of cognitive function for schizophrenic patients that consists of six tests: verbal memory,
Correspondence: Norio Yasui-Furukori Department of Neuropsychiatry, Hirosaki University Graduate School of Medicine, Hirosaki 036-8562, Japan

Email yasufuru@cc.hirosaki-u.ac.jp 
working memory, motor speed, verbal fluency, attention, and executive function. ${ }^{1}$ The BACS is fully portable, and the time required for testing is only approximately 30 minutes with minimal extra time for scoring and training demands. ${ }^{7}$ Therefore it has fewer burdens, and it is possible to complete the test in more cases, compared to the MATRICS consensus cognitive Battery. ${ }^{8}$ There are many studies that have compared BACS score before and after medication of antipsychotics. ${ }^{9-11}$ However, there are few studies that have investigated which factor, disease or aging, is a better determinant of cognitive function in schizophrenic patients using the BACS. Therefore the present study aimed to investigate the influences of disease and aging on BACS performance in schizophrenic patients using subjects with a wide range of ages.

\section{Methods}

\section{Participants}

A total of 222 schizophrenic patients who were diagnosed according to the Diagnostic and Statistical Manual of Mental Disorders, 4th edition (DSM-IV) ${ }^{12}$ and received medication as outpatients $(n=78)$ or inpatients $(n=144)$ were recruited from the Hospital of Hirosaki University School of Medicine ( $\mathrm{n}=99)$, Hirosaki-Aiseikai Hospital $(\mathrm{n}=113)$, and Kuroishi-Akebono Hospital $(\mathrm{n}=10)$. Of these 222 patients, 74 patients failed to complete all examinations or demonstrate an appropriate intelligence level; hence, 148 patients completed the study.

We also recruited 150 premorbid intelligence-levelmatched healthy individuals as a comparison group. They had no psychiatric history or current psychiatric complaints. The majority of the comparison group was employed as medical staff, such as a nurse, nursing assistant, dietician, occupational therapist, or psychiatric social worker at Hirosaki-Aiseikai Hospital and Kuroishi-Akebono Hospital. The characteristics of the two groups are shown in Table 1. There were significant differences between patients and comparison subjects with regard to age, level of education, and gender ratio. The mean age of patients was significantly higher than that of the comparisons. The level of education of the comparisons was significantly higher than that of the patients.

The data collection for this study was approved by the Ethics Committee of Hirosaki University School of Medicine, and all subjects provided written informed consent before participating.

\section{Procedure}

The Japanese version of the National Adult Reading Test $(\text { JART })^{13}$ was also given to all subjects for the purpose to exclude mental retardation. The JART, standardized by Matsuoka et al, reflects premorbid IQs in Japanese patients with schizophrenia. ${ }^{14}$

\section{Statistical analysis}

Differences in characteristics between the schizophrenic patients and the comparison group were analyzed using $t$-tests and Chi-square tests. A multiple regression analysis of the possible correlations between the six tasks of the BACS-J (verbal memory, working memory, motor speed, attention, verbal fluency, and executive function) or the composite score and the clinical variables were performed for each group and all subjects. In the comparison group analysis, the six tasks and the composite score of the BACS$\mathrm{J}$ were set as the dependent variables, whereas diagnosis, age, gender, and level of education were set as the independent variables. For the analyses of the patient group and all subjects, the six tasks and the composite score of the BACS-J were set as the dependent variables, whereas diagnosis, age, gender, level of education, and duration of illness were set as the independent variables. A $P$-value of $<0.05$ was considered statistically significant. All analyses were performed using SPSS 17.0J for Windows (IBM Corporation, Armonk, NY, USA).

Table I Characteristics of comparison group and schizophrenic subjects

\begin{tabular}{|c|c|c|c|}
\hline & $\begin{array}{l}\text { Comparison } \\
(n=150)\end{array}$ & $\begin{array}{l}\text { Schizophrenia } \\
(n=148)\end{array}$ & Significances \\
\hline Age (years) & $36.6 \pm 11.5(20-64)$ & $40.0 \pm 14.0(20-77)$ & $\mathrm{t}_{296}=-2.230, P<0.05^{\mathrm{a}}$ \\
\hline Sex (male/female) & $39 / 111$ & $65 / 83$ & $x^{2}(I)=10.528, P<0.0 I^{b}$ \\
\hline Level of education (years) & $13.9 \pm 2.1(9-19)$ & $12.6 \pm 1.8(7-17)$ & $\mathrm{t}_{286}=5.585, P<0.00 \mathrm{I}^{\mathrm{a}}$ \\
\hline Level of premorbid intelligence & $99.9 \pm 7.5$ & $99.9 \pm 8.1$ & $\mathrm{t}_{296}=0.046, P=0.963^{\mathrm{a}}$ \\
\hline Age of onset & - & $27.1 \pm 10.7(12-64)$ & \\
\hline Duration of illness (years) & - & $13.0 \pm 12.9(0-56)$ & - \\
\hline Duration of treatment (years) & - & $11.1 \pm 12.8(0-56)$ & - \\
\hline
\end{tabular}

Notes: Data show mean \pm standard deviation (range). ${ }^{\mathrm{a}} \mathrm{t}$-test was used; ${ }^{\mathrm{b}} \mathrm{Chi}$-square test was used. 


\section{Results}

The mean \pm standard deviation of the BACS score for all subjects is shown in Table 2. Z-scores, standardized BACS results, whereby the mean of comparison was set to zero and the standard deviation set to one were also shown in Table 2.

Table 3 shows the result of the multiple regression analysis for each group. For the comparison group, age was found to influence five tasks of the BACS (verbal memory, working memory, attention, verbal fluency, and executive function) and the composite score. The level of education influenced two tasks (verbal memory and motor speed) and the composite score; and gender influenced only the executive function task. For the schizophrenic patient group, the duration of illness influenced four tasks (working memory, motor speed, attention, and executive function) and the composite score. In addition, patient age influenced three tasks (attention, verbal fluency, and executive function) and the composite score; the level of education influenced two tasks (attention and verbal fluency) and the composite score; and gender influenced only the executive function task. Table 4 shows the results of the multiple regression analysis for all subjects, in which disease was found to influence all six tasks of performance

Table 2 The mean \pm SD of the BACS for all subjects

\begin{tabular}{llc}
\hline BACS & Mean of raw score & Mean of z-score \\
\hline Verbal memory & & \\
Sz & $30.2 \pm 12.4$ & $-1.67 \pm 1.28$ \\
Comp & $46.2 \pm 9.8$ & $-0.1 \pm 1.0$ \\
Working memory & & \\
Sz & $15.3 \pm 4.4$ & $-1.13 \pm 1.05$ \\
Comp & $20.0 \pm 4.3$ & $0.0 \pm 1.0$ \\
Motor speed & & \\
Sz & $68.5 \pm 17.5$ & $-2.47 \pm 1.82$ \\
Comp & $91.9 \pm 9.8$ & $0.0 \pm 1.0$ \\
Attention & & \\
Sz & $45.5 \pm 13.9$ & $-2.11 \pm 1.32$ \\
Comp & $67.4 \pm 10.5$ & $0.0 \pm 1.0$ \\
Verbal fluency & & \\
Sz & $34.2 \pm 11.7$ & $-1.19 \pm 1.23$ \\
Comp & $44.5 \pm 8.9$ & $-0.1 \pm 0.9$ \\
Executive function & & $-1.17 \pm 1.79$ \\
Sz & $15.0 \pm 4.5$ & $0.0 \pm 1.0$ \\
Comp & $17.8 \pm 2.5$ & $-1.50 \pm 1.02$ \\
Composite score & & $0.0 \pm 0.6$ \\
Sz & - & \\
Comp & - & \\
\hline
\end{tabular}

Notes: a Mean score \pm SD; ba composite score was calculated by averaging al z-scores of the six primary tasks from the BACS-J.

Abbreviations: BACS, Brief Assessment of Cognition in Schizophrenia; BACS-J, Japanese language version of the BACS; Comp, comparison group; SD, standard deviation; Sz, schizophrenic group. and the composite score. In addition, age influenced five tasks (verbal memory, working memory, attention, verbal fluency, and executive function) and the composite score; and the level of education influenced four tasks (verbal memory, motor speed, attention, and verbal fluency) and the composite score. The duration of illness also influenced four tasks (working memory, motor speed, attention, and executive function) and the composite score; and gender influenced two tasks (working memory and executive function) and the composite score.

\section{Discussion}

The present study sought to investigate the influences of disease and aging on performance on the BACS in schizophrenic patients. The results of the multiple regression analysis of all subjects indicated that almost all BACS performance components were attributable not only to disease but also aging, level of education, and duration of illness.

The results from the multiple regression analysis of the comparison group showed that age was the strongest factor influencing almost all BACS tasks and the composite score (Table 3). On the other hand, the results from the patient group analysis indicated that the influence of the duration of illness was stronger than that of age for many BACS tasks and the composite score and that the influence of age was diminished. Furthermore, the standardized regression coefficients of the diagnosis for the analysis of all subjects were large for almost all BACS tasks and the composite score (Table 4). These results suggest that BACS performance among schizophrenic patients is more strongly influenced by disease than age. The BACS is commonly used to assess aspects of cognition found to be most impaired and most strongly correlated with prognosis in patients with schizophrenia. ${ }^{1}$ Accordingly, our results indicate that the BACS can serve as a specific assessment tool for the analysis of schizophrenia in a Japanese sample population.

However, the present study found that almost all BACS performance tasks and the composite scores of patients with higher levels of education and a younger age were superior to those of subjects with lower education levels and an older age, and these results are inconsistent with those of a previous study. In particular, Kishi et al reported no influence of age and education level on many aspects of cognitive function, but did detect an influence for the Positive and Negative Syndrome Scale (PANSS) composite score and three tasks of the BACS (verbal memory, working memory, and executive function). ${ }^{15}$ However, the relationship between cognitive function and age and level of education 
Table 3 Factors that influenced the BACS scores in the comparison group and schizophrenic subjects

\begin{tabular}{|c|c|c|c|c|c|c|c|c|c|}
\hline \multirow[t]{2}{*}{ Condition } & \multirow[t]{2}{*}{ Variable } & \multicolumn{4}{|c|}{ Comparison } & \multicolumn{4}{|c|}{ Schizophrenia } \\
\hline & & Beta & $t$ & $P$ & $\mathbf{R}$ & Beta & $t$ & $P$ & $\mathbf{R}$ \\
\hline \multirow[t]{4}{*}{ Verbal memory } & Age & -0.417 & -5.499 & 0.000 & & -0.205 & $-1.79 \mid$ & 0.076 & \\
\hline & Gender & 0.055 & 0.757 & 0.451 & 0.523 & 0.062 & 0.767 & 0.444 & 0.389 \\
\hline & Education & 0.228 & 3043.000 & 0.003 & $P=0.000$ & 0.126 & 1.543 & 0.125 & $P=0.000$ \\
\hline & Duration of illness & - & - & - & & -0.175 & -1.524 & 0.130 & \\
\hline \multirow[t]{4}{*}{ Working memory } & Age & -0.364 & -4.528 & 0.000 & & -0.178 & -1.627 & 0.106 & \\
\hline & Gender & -0.143 & -1.845 & 0.067 & 0.427 & -0.122 & -1.574 & 0.118 & 0.475 \\
\hline & Education & 0.015 & 0.187 & 0.852 & $P=0.000$ & 0.115 & 1.467 & 0.145 & $P=0.000$ \\
\hline & Duration of illness & - & - & - & & -0.290 & -2.637 & 0.009 & \\
\hline \multirow[t]{4}{*}{ Motor speed } & Age & 0.074 & $0.86 \mathrm{I}$ & 0.390 & & -0.159 & -1.517 & 0.132 & \\
\hline & Gender & -0.079 & -0.952 & 0.343 & 0.252 & -0.026 & -0.342 & 0.733 & 0.534 \\
\hline & Education & 0.242 & 2.841 & 0.050 & $P=0.022$ & 0.09 & 1.203 & 0.231 & $P=0.000$ \\
\hline & Duration of illness & - & - & - & & -0.392 & -3.708 & 0.000 & \\
\hline \multirow[t]{4}{*}{ Attention } & Age & $-0.47 \mid$ & -6.313 & 0.000 & & -0.314 & -3.357 & 0.001 & \\
\hline & Gender & -0.075 & -1.045 & 0.298 & 0.544 & -0.056 & -0.840 & 0.403 & 0.657 \\
\hline & Education & 0.114 & 1.538 & 0.126 & $P=0.000$ & 0.188 & 2.802 & 0.006 & $P=0.000$ \\
\hline & Duration of illness & - & - & - & & -0.346 & -3.669 & 0.000 & \\
\hline \multirow[t]{4}{*}{ Verbal fluency } & Age & -0.333 & -4.139 & 0.000 & & -0.265 & -2.292 & 0.023 & \\
\hline & Gender & -0.097 & -1.248 & 0.214 & 0.428 & -0.038 & -0.460 & 0.646 & 0.358 \\
\hline & Education & 0.035 & 1.577 & 0.117 & $P=0.000$ & 0.176 & 2.118 & 0.036 & $P=0.001$ \\
\hline & Duration of illness & - & - & - & & -0.041 & -0.353 & 0.725 & \\
\hline \multirow[t]{4}{*}{ Executive function } & Age & -0.204 & -2.427 & 0.016 & & -0.245 & -2.317 & 0.022 & \\
\hline & Gender & -0.175 & -2.155 & 0.033 & 0.330 & -0.209 & -2.779 & 0.006 & 0.523 \\
\hline & Education & 0.074 & 0.889 & 0.376 & $P=0.001$ & 0.135 & 1.779 & 0.078 & $P=0.000$ \\
\hline & Duration of illness & - & - & - & & -0.240 & -2.253 & 0.026 & \\
\hline \multirow[t]{4}{*}{ Composite score } & Age & -0.431 & -5.749 & 0.000 & & -0.292 & -2.978 & 0.003 & \\
\hline & Gender & -0.131 & $-1.85 \mid$ & 0.066 & 0.567 & -0.089 & -1.269 & 0.207 & 0.613 \\
\hline & Education & 0.196 & 2.704 & 0.008 & $P=0.000$ & 0.186 & 2.651 & 0.009 & $P=0.000$ \\
\hline & Duration of illness & - & - & - & & -0.313 & -3.172 & 0.002 & \\
\hline
\end{tabular}

Abbreviation: BACS, Brief Assessment of Cognition in Schizophrenia.

has been reported in many previous studies. ${ }^{1,4,16}$ In the study by Kishi et al, clinical factors (age, sex, duration of illness, level of education, smoking status, the PANSS score, and medication dosage) served as the independent variables. ${ }^{15}$ Therefore, the inconsistencies between the results of the present study and those of Kishi et al may be attributable to differences in the variables used for analysis. Furthermore, this previous study found that the influence of the PANSS was much greater than that of other factors such as age or level of education. ${ }^{15}$

The present study did not detect any influence of age but did identify that the level of education influenced the participants' motor speed in the comparison and all subject analyses. Furthermore, Ruff and Parker and Era et al reported similar results concerning the relationship between additional education and faster performance, ${ }^{17,18}$ and the relationship between motor speed and level of education was also suggested by Jones et al. ${ }^{19}$ These previous authors reported that sulcus fluid volume, education level, and a measure of general psychiatric symptomology obtained by linear structural relations analysis that relates brain and psychosocial functions to cognitive functioning were significantly related to speed. In addition, Ruff and Parker and Era et al also reported the relationship between age and motor speed, ${ }^{17,18}$ and Keefe et al reported an association between age and motor speed in the BACS task. ${ }^{1}$ The reason for these inconsistencies between the present study and previous studies concerning the influence of age on motor speed is unclear, although it is possible that the level of education more strongly influences motor speed than age. The influence of education on attention tasks was also shown in the results of the patient group and the all subjects group. From a meta-analysis, one previous study reported the relationship between attention ability and the reduction in gray matter volume. ${ }^{20}$ Furthermore, Piras et al reported that for the hippocampus, regions of gray matter may be related to level of education. ${ }^{21}$ Accordingly, the results of the present study may support these findings. On the other hand, the results of the present study were inconsistent with those of Kishi et al and Jolfael et al, which analyzed the relationship between cognition (eg, attention) and clinical 
Table 4 Factors that influenced the BACS scores

\begin{tabular}{|c|c|c|c|c|c|}
\hline Condition & Variable & Beta & $t$ & $P$ & $\mathbf{R}$ \\
\hline \multirow[t]{5}{*}{ Verbal memory } & Disease & -0.439 & $-7.56 \mid$ & 0.000 & \\
\hline & Age & -0.268 & -4.993 & 0.000 & \\
\hline & Gender & 0.046 & 1.000 & 0.318 & 0.676 \\
\hline & Education & 0.161 & 3.377 & 0.001 & $P=0.000$ \\
\hline & $\begin{array}{l}\text { Duration } \\
\text { of illness }\end{array}$ & -0.074 & -1.149 & 0.252 & \\
\hline \multirow[t]{5}{*}{ Working memory } & Disease & -0.353 & -5.653 & 0.000 & \\
\hline & Age & -0.256 & -4.436 & 0.000 & \\
\hline & Gender & -0.124 & -2.530 & 0.012 & 0.611 \\
\hline & Education & 0.072 & $\mathrm{I} .40 \mathrm{I}$ & 0.162 & $P=0.000$ \\
\hline & $\begin{array}{l}\text { Duration } \\
\text { of illness }\end{array}$ & -0.155 & -2.249 & 0.025 & \\
\hline \multirow[t]{5}{*}{ Motor speed } & Disease & -0.374 & -6.914 & 0.000 & \\
\hline & Age & -0.038 & -0.754 & 0.452 & \\
\hline & Gender & -0.029 & -0.682 & 0.496 & 0.728 \\
\hline & Education & 0.104 & $2.34 I$ & 0.020 & $P=0.000$ \\
\hline & $\begin{array}{l}\text { Duration } \\
\text { of illness }\end{array}$ & -0.389 & -6.500 & 0.000 & \\
\hline \multirow[t]{5}{*}{ Attention } & Disease & -0.475 & -10.180 & 0.000 & \\
\hline & Age & -0.289 & -6.697 & 0.000 & \\
\hline & Gender & -0.052 & -1.412 & 0.159 & 0.806 \\
\hline & Education & 0.125 & 3.251 & 0.001 & $P=0.000$ \\
\hline & $\begin{array}{l}\text { Duration } \\
\text { of illness }\end{array}$ & -0.221 & -4.279 & 0.000 & \\
\hline \multirow[t]{5}{*}{ Verbal fluency } & Disease & -0.363 & -5.566 & 0.000 & \\
\hline & Age & -0.261 & -4.338 & 0.000 & \\
\hline & Gender & -0.059 & -1.140 & 0.255 & 0.563 \\
\hline & Education & 0.144 & 2.684 & 0.008 & $P=0.000$ \\
\hline & $\begin{array}{l}\text { Duration } \\
\text { of illness }\end{array}$ & -0.032 & -0.448 & 0.655 & \\
\hline \multirow[t]{5}{*}{ Executive function } & Disease & -0.190 & -2.938 & 0.004 & \\
\hline & Age & -0.178 & -2.966 & 0.003 & \\
\hline & Gender & -0.182 & -3.561 & 0.000 & 0.571 \\
\hline & Education & 0.092 & 1.734 & 0.084 & $P=0.000$ \\
\hline & $\begin{array}{l}\text { Duration } \\
\text { of illness }\end{array}$ & -0.287 & -4.004 & 0.000 & \\
\hline \multirow[t]{5}{*}{ Composite score } & Disease & -0.453 & -9.477 & 0.000 & \\
\hline & Age & -0.252 & -5.700 & 0.000 & \\
\hline & Gender & $-0.08 \mathrm{I}$ & -2.145 & 0.033 & 0.795 \\
\hline & Education & 0.148 & 3.765 & 0.000 & $P=0.000$ \\
\hline & $\begin{array}{l}\text { Duration } \\
\text { of illness }\end{array}$ & -0.241 & -4.553 & 0.000 & \\
\hline
\end{tabular}

Abbreviation: BACS, Brief Assessment of Cognition in Schizophrenia.

profiles (eg, age, gender, level of education, and severity of symptoms) in schizophrenic patients. ${ }^{15,22}$ These inconsistencies between the present study and previous studies may have been caused by differences in dependent variables.

The gender influence on executive functions in the BACS tasks was evaluated for the comparison, patient, and all subject groups. Gender was shown to influence working memory and the composite score of all subjects; in particular, males showed better performance on both the BACS tasks and the composite score as compared to females. This result is similar to that of Roesch-Ely et al, who reported that female schizophrenic patients showed worse performance in executive control as compared to male patients. ${ }^{23}$ In contrast, Leung and Chue reviewed the opposite result as reported by Seidman et al and Goldstein et al. ${ }^{24-26}$ The reason for these inconsistent results may have been due to differences in the examination method. For example, the Tower of London procedure, which was the method used in the present study, is used to specifically evaluate planning ability, whereas the method used by Roesch-Ely et al is a dual performance task that selects high auditory stimulus tones and responds to several types of stimuli and addresses attention ability. ${ }^{23}$ In contrast, the method used by Seidman et al and Goldstein et al was the Wisconsin Card Sorting Test (WCST), which evaluates the ability of set-shifting. ${ }^{23,26}$ Accordingly, further studies should compare the differences among several types of executive tasks. The current study also revealed the influence of gender on working memory in all subjects. Although one previous study also reported that male patients performed better than females on visual working memory tasks, ${ }^{27}$ Lecardeur et al reported the opposite result after examining spatial working memory. ${ }^{28}$ Furthermore, Minor and Park reported an absence of gender differences on spatial working memory, ${ }^{29}$ and Bozikas et al and Roesch-Ely et al reported the absence of gender differences on working memory. ${ }^{4,23}$ Related to these inconsistencies among studies that have analyzed working memory, the reason for the influence of gender on working memory shown in the present study remains unclear.

There were also several limitations to our study. First, the design of this study was cross-sectional. Therefore, future longitudinal studies should take into consideration the accelerated cognitive decline that occurs in patients over 60 years of age in both healthy samples ${ }^{4,5}$ and schizophrenic samples, ${ }^{2}$ and these studies should also investigate the influence of disease and aging. Second, we were not able to examine the influence of other clinical profiles on the scores of the BACS because of the lack of these data. Several previous studies have reported correlations between the BACS score and clinical factors such as differences in medications, ${ }^{24,25}$ severity of symptoms,${ }^{13}$ subtypes of schizophrenic disease, ${ }^{26}$ duration of untreated psychosis, ${ }^{27}$ and patient age at onset. ${ }^{28}$ Therefore, further studies considering the influences of these clinical profiles are needed.

\section{Conclusion}

In conclusion, the results of this study suggest that BACS performance in schizophrenic patients is influenced not only by disease. 


\section{Acknowledgment}

This work was partly supported by a grant from Hirosaki Research Institute for the neurosciences. We would like to thank Norio Sugawara, Manabu Saito, Yasushi Sato, and Hanako Furukori, Shoko Tsuchimine. NS conducted the statistical analysis, and interpreted the data. MS, YS, and HF completed initial survey construction, and recruitment of participants. ST participated in the data collection, and the interpretation of the results.

\section{Disclosure}

The authors report no conflicts of interest in this work.

\section{References}

1. Keefe RS, Goldberg TE, Harvey PD, Gold JM, Poe M, Coughenour L. The Brief Assessment of Cognition in Schizophrenia: reliability, sensitivity, and comparison with a standard neurocognitive battery. Schizophr Res. 2004;68(2-3):283-297.

2. Harvey PD, Silverman JM, Mohs RC, et al. Cognitive decline in late-life schizophrenia: a longitudinal study of geriatric chronically hospitalized patients. Biol Psychiatry. 1999;45(1):32-40.

3. Loewenstein DA, Czaja SJ, Bowie CR, Harvey PD. Age-associated differences in cognitive performance in older patients with schizophrenia: a comparison with healthy older adults. Am J Geriatr Psychiatry. 2012; 20(1):29-40.

4. Bozikas VP, Giazkoulidou A, Hatzigeorgiadou M, Karavatos A, Kosmidis MH. Do age and education contribute to performance on the clock drawing test? Normative data for the Greek population. J Clin Exp Neuropsychol. 2008;30(2):199-203.

5. Sugawara N, Yasui-Furukori N, Umeda T, et al. Clock drawing performance in a community-dwelling populations. Normative data for Japanese subjects. Aging Ment Health. 2010;14(5):587-592.

6. Kaneda A, Yasui-Furukori N, Umeda T, et al. Comparing the influences of age and disease on distortion in the Clock Drawing Test in Japanese patients with schizophrenia. Am J Geriatr Psychiatry. 2010;18(10): 908-916.

7. Kaneda Y, Sumiyoshi T, Keefe R, Ishimoto Y, Numata S, Ohmori T. Brief assessment of cognition in schizophrenia: varidation of the Japanese version. Psychiatry Clin Neurosci. 2007;61(6):602-609.

8. Keefe RS, Goldberg TE ,Harvey PD, et al:The Brief Assessment of Cognition in Schizophrenia:reliability sensitivity and comparison with a standard neurocognitive battery. Schizophr Res. 2004;68:283-297.

9. Keefe RS, Harvey PD, Goldberg TE, et al. Norms and standardization of the Brief Assessment of Cognition in Schizophrenia (BACS). Schizophr Res. 2008;102(1-3):108-115.

10. Elie D, Poirier M, Chianetta J, Durand M, Grégoire C, Grignon S. Cognitive effects of antipsychotic dosage and polypharamacy: a study with the BACS in patients with schizophrenia and schizoaffective disorder. J Psychopharmacol. 2010;24(7):1037-1044.

11. Yasui-Furukori N, Kaneda A, Sugawara N, Tomita T, Kaneko S. Effect of adjunctive treatment with aripiprazole to atypical antipsychotics on cognitive function in schizophrenia patients. J Psychopharmacol. 2012; 26(6):806-812.

Neuropsychiatric Disease and Treatment

\section{Publish your work in this journal}

Neuropsychiatric Disease and Treatment is an international, peerreviewed journal of clinical therapeutics and pharmacology focusing on concise rapid reporting of clinical or pre-clinical studies on a range of neuropsychiatric and neurological disorders. This journal is indexed on PubMed Central, the 'PsycINFO' database and CAS.
12. American Psychiatric Association. Diagnostic and Statistical Manual of Mental Disorders: DSM-IV, 4th ed. Washington, DC: American Psychiatric Association; 1994.

13. Matsuoka K, Uno M, Kasai K, Koyama K, Kim Y. Estimation of premorbid IQ in individuals with Alzheimer's disease using Japanese ideographic script (Kanji) compound words: Japanese version of National Adult Reading Test. Psychiatry Clin Neurosci. 2006;60(3): 332-339.

14. Uetsuki M, Matsuoka K, Kim Y, et al. Estimation of premorbid IQ by JART in schizophrenia. Seishin Igaku. 2006; 48(1):15-22. Japanese.

15. Kishi T, Moriwaki M, Kawashima K, et al. Investigation of clinical factors influencing cognitive function in Japanese schizophrenia. Neurosci Res. 2010;66(4):340-344.

16. Irani F, Kalkstein S, Moberg EA, Moberg PJ. Neuropsychological performance in older patients with schizophrenia: A meta-analysis of cross-sectional and longitudinal studies. Schizophr Bull. 2011;37(6): 1318-1326.

17. Ruff RM, Parker SB. Gender- and age-specific changes in motor speed and eye-hand coordination in adults: normative values for the Finger Tapping and Grooved Pegboard Tests. Percept Mot Skills. 1993; 76(3 Pt 2):1219-1230.

18. Era P, Sainio P, Koskinen S, Ohlgren J, Härkänen T, Aromaa A. Psychomotor speed in a random sample of 7,979 subjects aged 30 years and over. Aging Clin Exp Res. 2011;23(2):135-144.

19. Jones KJ, Albert MS, Duffy FH, Hyde MR, Naeser M, Aldwin C. Modeling age using cognitive, psychosocial and physiological variables: the Boston normative aging study. Exp Aging Res. 1991;17(4):227-242.

20. Dickinson D, Ramsey ME, Gold JM. Overlooking the obvious. A metaanalytic comparison of digit symbol coding tasks and other cognitive measures in schizophrenia. Arch Gen Psychiatry. 2007;64(5):532-542.

21. Piras F, Cherubini A, Caltagirone C, Spalletta G. Education mediates microstructural change in bilateral hippocampus. Hum Brain Mapp. 2011;32(2):282-289.

22. Jolfaei AG, Moshki P, Asgharpour M, Moshki H. The relationship between Attention/Vigilance and Symptom Severity in Schizophrenic Patients. Iran J Psychiatry. 2012;7(1):22-25.

23. Roesch-Ely D, Hornberger E, Weiland S, et al. Do sex differences affect prefrontal cortex associated cotnition in schizophrenia? Schizophr Res. 2009; 107(2-3):255-261.

24. Leung A, Chue P. Sex differences in schizophrenia, a review of the literature. Acta Psychiatr Scand Suppl. 2000;401:3-38.

25. Seidman LJ, Goldstein JM, Goodman JM, et al. Sex differences in olfactory identification and Wisconsin Card Sorting performance in schizophrenia: relationship to attention and verbal ability. Biol Psychiatry. 1997;42(2):104-115.

26. Goldstein JM, Seidman LJ, Goodman JM, et al. Are there sex differences in neuropsychological functions among patients with schizophrenia? Am J Psychiatry. 1998;155(10):1358-1364.

27. Torniainen M, Suvisaari J, Partonen T, et al. Sex differences in cognition among persons with schizophrenia and healthy first-degree relatives. Psychiatry Res. 2011;188(1):7-12.

28. Lecardeur L, Mendrek A, Stip E. Sexual dimorphism of spatial working memory profiles in schizophrenia. Cogn Neuropsychiatry. 2010;15(4): $397-405$.

29. Minor K, Park S. Spatial working memory: Absence of gender differences in schizophrenia patients and healthy control subjects. Biol Psychiatry. 1999;46:1003-1005.

The manuscript management system is completely online and includes a very quick and fair peer-review system, which is all easy to use. Visit http://www.dovepress.com/testimonials.php to read real quotes from published authors. 